\title{
Georges Cuvier's appeal for international collaboration, 1800
}

Honorary Senior Member, IUGS International Commission on the History of Geological Sciences (INHIGEO), 2 Welsh Street, Bishop's Castle, Shropshire SY9 5BT, UK; *Corresponding author, E-mail: mjsr100uk@gmail.com

(Received: October 31, 2021; Revised accepted: January 10, 2022)

https://doi.org/10.18814/epiiugs/2022/022002

Georges Cuvier (1769-1832) was one of the most outstanding scientific 'savants' of his time. His work on comparative anatomy was dramatically deepened by his study of the bones of fossil mammals and reptiles, many of which he showed were distinct from those of any living species, thereby claiming a major role for extinction in the history of life on Earth. In 1800 he wrote a preliminary report on his research, appealing to others around the world to contribute to it by sending him accurate images of further fossil bones. This appeal was highly successful, and illustrates the character of the international scientific community at the start of the 19th century. Cuvier's prospectus, given here in English translation, is a landmark of pivotal significance in the history of the Earth sciences.

\section{Introduction}

Georges Cuvier (1769-1832) was by any reckoning a towering figure in the scientific world of the early 19th century. Although he was primarily a comparative anatomist, and one of outstanding importance in the history of biology, his pioneer research on fossil mammals led him into what was then the novel science of 'geology'. He argued strongly for the reality of extinction as a perennial feature of the natural world, and he linked this with a view of geological change that stressed the impact of 'revolutions', or major physical changes of any kind, at or beneath the Earth's surface. More profoundly, Cuvier saw his research as 'bursting the limits of time', by making it possible to reconstruct a reliable and detailed history of the Earth and its life, long before the beginnings of human records or even the existence of human beings. His research had its greatest impact through the highly readable Discours Préliminaire that he prefixed to his collected papers on fossil bones (Recherches sur les Ossemens Fossiles, first edition 1812). But that was the culmination of a research project that he had begun before the turn of the century.

As a young man, Cuvier had a meteoric rise to prominence among 'savants' - it would be anachronistic to call them 'scientists' - in France, which was then the world centre of all the sciences, in the wake of its dramatic political Revolution a few years earlier. He had been appointed to a junior position at the newly established Muséum d'Histoire Naturelle in Paris, which became his research centre (and his home) for the rest of his life. Although his earliest work had been on invertebrates, particularly the then poorly understood molluscs, he had soon turned to the mammals and other 'quadrupeds', and he had his permanent position defined as 'comparative anatomy'. Chance events then brought to his attention the fossil bones that several older savants had been studying in previous decades. Within a few years he had made spectacular progress in describing what looked like a diverse fauna of fossil mammals and reptiles, most of them apparently distinct from any species known alive and therefore - so he claimed - likely to be extinct. In 1795 he had been appointed the youngest member of the 'First Class' (for the natural sciences) of the new National Institute, which after the Revolution had replaced the old Royal Academy of Sciences. It was to this distinguished body that on 12 November 1800 he presented a preliminary 'prospectus' on his research on fossil bones. This included an appeal for the collaboration of other savants in France and beyond. Cuvier's prospectus is the paper printed here in English translation.

Cuvier opened his report with what 'everyone' - meaning primarily his audience of savants of all kinds - already knew, namely that the Earth shows unmistakeable signs of major physical changes in its distant past. These had long been the subject of lively debate and speculation; but Cuvier contrasted the tradition of proposing a conjectural 'system', or all-explanatory 'theory of the Earth' (a genre in which James Hutton's work with that title is now the best-known example), with the much more recent development of research focussed on rigorous observation of some specific class of evidence, based above all on intensive fieldwork. Cuvier's dismissal of the former approach as outdated, and his approval of the latter, was made clear in his contrast between 'fragile edifices' and 'solid foundations', and in his analogy with the transition from myths about the past to reliable human history. Cuvier then introduced the fossil bones of quadrupeds as being a topic of outstanding importance, because they might help solve a problem at the heart of the sciences of nature. The contrasts between fossils and living organisms might be due to the outright extinction of the former, or to their 'modification' (in modern terms, evolution) into the living species, or to the 'transport' of organisms from one part of the world to another, either in some sudden and violent event or just in a slow migration from one habitat to another. These were regarded as alternative explanations for the same unexpected observation, namely the lack of identity between fossil and living species (it is important to note that evolution was treated at this time as just one possibility among others, and not obviously the most plausible one). 
Cuvier introduced his own chosen field of research as one of crucial importance, because most of the living species of mammals, and especially the large terrestrial ones, were already well known; and an exceptionally comprehensive set of their skeletons was available to him in the Muséum, to act as a reference collection for comparison with fossil bones. He explained how the close integration of structure and function in living organisms could be used in this case to reconstruct the skeletons - and even to infer the likely habits and ways of life - of fossil mammals, and above all to determine whether or not they were species distinct from any known alive. He claimed that many fossil mammals were demonstrably different from their living relatives, and that they, or at least the large terrestrial ones, were therefore likely to be extinct. It was in fact through his own early research on the comparative anatomy of fossil mammals that he had already claimed that the South American megatherium had been a giant sloth, the Siberian mammoth an Arctic elephant distinct from either of the living tropical species, the North American mastodon still more distinct, and so on. He went on to list many more recent examples, carefully arranged according to the relative strength of the evidence, with the expectation that further research would add many, though perhaps not all, to the roster of those likely to be extinct.

To help in this further research, Cuvier appealed to the worldwide community of savants for practical assistance of a specific kind. Like others at this time, he himself had from the start made intensive use of paper 'proxies' - his own accurate drawings of particular bones, ready to be reproduced by a professional engraver - to render his evidence mobile across the geographically scattered scientific world. To ask for the loan of the precious fossils themselves would have been hazardous at any time, but it was even more so during the seemingly endless Revolutionary and Napoleonic wars that were ravaging Europe and extending beyond it (and Napoleon was giving France a notorious reputation for seizing other nations' cultural and scientific assets). So Cuvier appealed to savants just to send him drawings of fossil bones in their possession, or those in museum collections to which they had access, to enlarge the range of specimens on which his own expert conclusions could be based. He offered to defray their expenses in doing so, and promised to acknowledge in print their contributions to his work. Those he named in his prospectus (they are identified and located in the footnotes to this translation) reveal the remarkable geographical spread of the informants he had already recruited, and of course he hoped to add many more; they illustrate the highly international and multilingual character of the scientific community at this time (and hence the limitations of modern historical research that is confined to a single nation-state or to primary sources in just one language).

The relevant Class of the National Institute - or at least those members with influence in the matter - recognised at once the outstanding importance of Cuvier's research and of his appeal. They gave his prospectus exceptional treatment by ordering it to be printed as a pamphlet and distributed internationally to appropriate 'savants and amateurs': that is, not only to established naturalists, anatomists and other scholars, most of them teaching in universities, but also to others - not 'amateurs' in the modern pejorative sense - who had had the time, the means and the enthusiasm to have assembled important private collections of fossils. In the event, Cuvier's appeal successfully transcended the obstacles thrown up by the wars: for example one copy was sent to Joseph
Banks, the president of the Royal Society in London, although his nation was at war with France; it was also reprinted in three scientific periodicals, two French and one Italian, and extracts were published in German and English ones. Cuvier's appeal was certainly successful: many accurate drawings of fossil bones, some of them handcoloured in trompe-l'oeil style, converged on his workplace in Paris from all around Europe and even more distant parts of the world; and many were duly incorporated, alongside his own drawings, in the engraved plates he published subsequently.

The work outlined in Cuvier's prospectus became his major research project in the following years. His results were published in a steady stream of densely illustrated papers in the Muséum's own inhouse Annales. As already mentioned, these were later reprinted in his great four-volume Ossemens Fossiles, which was itself enlarged and updated during the rest of his life; and the significance of his study was spelt out and expressed in terms accessible to both 'savants and amateurs', in successive editions of its Discours Préliminaire. In the life work of one of the most outstanding savants of his time, Cuvier's international 'appeal' of 1800 is a landmark of pivotal significance in the history of the Earth sciences.

\section{Cuvier's prospectus}

Extract from a work on the species of quadrupeds of which the bones have been found in the interior of the earth; addressed to savants and amateurs of the sciences, by G. Cuvier, member of the Institute, professor at the Collège de France and at the Panthéon central school, etc.

Printed by order of the Class for mathematical and physical sciences of the National Institute, on 26 brumaire, year 9 [of the French Republic, i.e.,17 November 1800].

Everyone now knows that the globe we live on displays almost everywhere the indisputable traces of vast revolutions: the varied products of living nature that embellish its surface are just covering

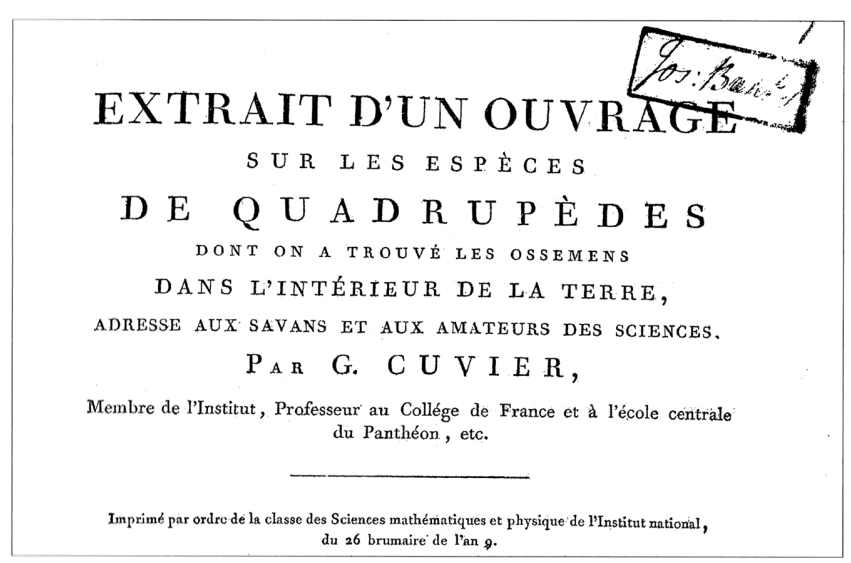

Figure 1. The printed heading of Cuvier's 'prospectus' (1800), in which he summarised the early progress of his research on fossil bones, and appealed to 'savants and amateurs of the sciences' to send him images of their specimens to add to his own. This particular copy was sent to Sir Joseph Banks, the president of the Royal Society in London (and marked with his library stamp); the war between France and England was not allowed to stop what Cuvier called the 'noble commerce' of scientific information exchanged internationally. (By permission of the British Library London: [B.352.(7)]) 
debris that bears witness to the destruction of an earlier nature. Whether one digs into the plains, or penetrates into caves in the mountains, or climbs their torn flanks, one encounters everywhere the remains of organisms, embedded in more or less thick beds that form the outer crust of the globe. Immense masses of shells are found at great distances from any sea, and at heights that it would be impossible for seas to reach today; beds of shale contain fish; seams of coal display the imprints of plants at heights or depths that are equally striking. But what is still more surprising is the disorder that reigns in the accumulation of these objects: here, shelly beds are covered by others that contain only plants; there, fish are superposed to terrestrial animals, and in turn have plants or shells above them. In other areas, lava flows and pumice stone, the products of subterranean fires, are mixed with products of the ocean. Almost everywhere these remains of organisms are utterly foreign to the climate of the ground that conceals them: it is in the tropics that one finds the living analogues of the fossil shells and fish of the north, and vice versa. In a word, just as nature has made the present habitats of living species attractive, and taken care to provide for their well-being and their conservation, so she seems to have been pleased to leave them with monuments of her power in this disorder and apparent confusion, and clear proofs of the upheavals that must have preceded the present order of the universe.

These traces of devastation have always been striking to the human spirit. The legends of deluges that are preserved among almost all peoples are due to the marine fossils scattered over the whole earth. Legends of giants - no less universal - derive from bones that are larger than those of any of the [living] animals of the climates in which they are found from time to time. But these are not just vulgar ideas. Men of another kind have sought to comprehend the whole generality of the phenomenon, in order to ascend to its causes. They have excavated in the ruins of the globe in order to find monuments of its physical history, just as antiquarians excavate in the ruins of cities in order to find monuments of the history of the crafts and customs of the people who lived there. The Woodwards, Whistons, Leibnizes and Buffons were unable to contemplate these objects without the disquiet that is a mark of genius. ${ }^{(1)}$ Their imagination, fired by such a grand spectacle, shot back into the past, and believed itself present at these successive catastrophes, inundations, subsidences and conflagrations; they believed they were tracing a history, when it was only that of their own creation.

Like men, however, the sciences have their stages of life. Given up in youth to brilliant imaginative illusions, they become cooler and more reasoned in maturity. The creative geniuses that give them birth thrust them into a career by a kind of inspiration, and they follow it almost recklessly; and it is necessarily so. Timid spirits would start by noticing the obstacles; but daring minds surmount them without perceiving them, and their example encourages the timid. They in turn become involved; their progress is slower, and they take no step without having recognized its difficulties and smoothed it out. The first (1)John Woodward (1665-1728), William Whiston (1667-1752) and Gottfried Wilhelm von Leibniz (1646-1716) had all published 'theories of the earth' long before; George Louis Leclerc, count de Buffon (1707-88), the most prominent French naturalist of a more recent generation, was implicitly sidelined by being associated with them; naming them all in the plural implied, correctly, that they were representative of many other such speculative 'theorists'. That they deserved to be called 'geniuses' was at best an ironic comment. guessed at nature rather than studying it; the others, while thinking they are only verifying the systems they admire, study it truly; and it is thus that the sciences - like peoples - pass from poetry to history.

The theory of the earth has thus taken a new direction in the past twenty years. The Saussures, Pallases and Dolomieus were less eager to attract the admiration of their contemporaries by brilliant but fragile edifices, than to set in place some solid foundations on which posterity could one day construct a lasting monument. ${ }^{(2)}$ They rejected all 'system'; they recognized that the first step to make in divining the past was to establish the present firmly. Since then, instead of imagining causes, one has collected facts. Mountains, veins and strata have been penetrated in all directions; one has assembled their materials and compared them with one another; and already we possess a mass of genuine knowledge that far surpasses all that could have been hoped for when this method began to find favour. ${ }^{(3)}$

There is however one part of the animal kingdom whose fossil remains have been less studied, namely the quadrupeds. Attention has long been given only to those fossil bones that are striking for their size or unusual form. Sloane, Messer-Schmidt, Daubenton and Pallas have thus made us aware of the bones of elephants and rhinoceros scattered in northern countries, and have given birth to the quite widespread idea that tropical animals formerly lived in the north or that they were swept there by some inundation that took that direction. ${ }^{(4)}$

Continuing this research, Camper, Blumenbach, Hunter, Rosenmüller and Faujas have well realised that such a cause is insufficient to explain all the phenomena, and that the distribution of the fossil bones is nothing like as regular as had been imagined; but they have not exhausted the matter. ${ }^{(5)}$ Comparing the number of species they have examined with those that still remain, it could almost be said that they have scarcely skimmed it.

\footnotetext{
${ }^{(2)}$ Horace Bénédict de Saussure (1740-99) had spent his life based in his native Geneva, but had explored the Alps very extensively, and had been the first savant to climb Mont Blanc; he had died only a year before Cuvier's address. Peter Simon Pallas (1741-1811) was a Prussian naturalist attached to the Academy of Sciences in St. Petersburg, who travelled widely in the Russian empire. Déodat Guy Silvain Tancrède Gratet de Dolomieu (1750-1801) had taught at the School of Mines in Paris, before joining Napoleon's Egyptian expedition. On his return journey in 1799 he had been taken prisoner-of-war; he was released a few months after Cuvier delivered this paper, and returned to Paris, but died soon afterwards. All three naturalists had been highly active in fieldwork. Like the theorists, they are named in the plural, to indicate that they are representative of the newer generation of careful observers.

${ }^{(3)}$ In this passage the French pronouns have been retained in translation, although this makes the English somewhat stilted: they show how Cuvier slides deftly from 'they' (the older naturalists), through the generalised 'one', to the 'we' that clearly includes himself.

${ }^{(4)}$ Sir Hans Sloane (1660-1753) had been a famous English naturalist whose vast and varied collections had become, after his death, the core of the new British Museum in London. Daniel Gottlieb Messerschmidt (1685-1735) had been a Prussian naturalist who travelled in Siberia.

${ }^{(5)}$ Petrus Camper (1722-89) had been an anatomist and professor of medicine at Groningen in the Netherlands. Johann Friedrich Blumenbach (1752-1840) was professor of medicine at Göttingen and a distinguished anatomist, naturalist and physical anthropologist. William Hunter (1718-83) had been a fashionable and wealthy surgeon in London, and had contributed to earlier debates on fossil bones. Johann Christian Rosenmüller (1771-1820) was professor of anatomy and surgery at Leipzig (and Cuvier's near-contemporary). Barthélemy Faujas de Saint-Fond (1741-1819) was the professor of 'geology' - the first savant anywhere to have that formal title - at the Muséum in Paris, and the author of a monograph on the fossils from the Chalk at Maastricht.
} 
However, this kind of fossil has no less interest than others for the theory of the earth; one could even say that it is easier to reach a decisive result by examining the bones of quadrupeds than by studying those of all other animal fossils. The principal question being to know the extent of the catastrophe that preceded the formation of our continents, it is above all a matter of determining whether the species that then existed have been entirely destroyed, or solely modified in form, or simply transported from one climate to another. ${ }^{(6)}$ Now it is clear that it should be easier to make such an examination in the case of the mammal class than on all the others: it is the least numerous, and we [already] know almost all its species. If there are still some to be discovered, they are surely small and unimportant. It is almost impossible that any of the large ones have escaped pursuit by travellers and the enquiries of naturalists. Furthermore, we now possess the skeletons of almost all that are known. We can thus compare, and decide with sufficient certainty whether any fossil bone does or does not resemble the analogous bone in living species. ${ }^{(7)}$ The case is not the same with shells and fish: naturalists are still far from having observed all of them; and each time we find an unknown [fossil] fish or shell in the earth we can [always] suppose that the species is still living in distant seas or at inaccessible depths. ${ }^{(8)}$

Despite these reasons for preferring the study of the fossil bones of quadrupeds, the distinguished men I named above have been hampered in their research by two kinds of difficulty. First, these bones are more difficult to collect than all other fossils, and are rarely found well preserved. The workmen who come across them give them little attention, because they take them for the bones of men or ordinary animals; often even savants have not perceived the subtle differences that distinguish them from those of common species. Second, it is not easy to establish the necessary comparisons everywhere. It is in effect just in our own day that comparative anatomy has emerged from infancy, and there are hardly two or three places in Europe where the collections are complete enough to contain all the specimens necessary for precise comparison. It is to these two causes that we should attribute the imperfection of our knowledge of the subject in question, and the errors that dominate [even] the most estimable works.

I have already mentioned the error that only the bones of tropical animals are found in the north. Several authors still think that these bones are exactly the same as those of living species; that they are never found except in loose deposits [terrains meubles], where they could have been transported by rivers; that South America has no fossils of animals of the tropical zone of the Old World, although there are some in North America; and that the Old World has no bones that belong to animals of the New. It is because the phenomenon has thus

\footnotetext{
${ }^{(6)}$ Cuvier's phrasing about a relatively recent 'catastrophe' is borrowed unmistakeably from the veteran Anglo-Genevan naturalist Jean-André Deluc [or de Luc] (1727-1817), with whose prolific works he was certainly familiar.

${ }^{(7)}$ Like other naturalists at this time, Cuvier uses the term 'analogous' to mean what was later distinguished as 'homologous'; that is (in this case) for bones that have the equivalent place in the skeleton, whether or not they had the same function and were 'analogous' in the later scientific sense.

${ }^{(8)}$ The 'living fossil' explanation - that any fossil species unknown alive might in fact still be flourishing in an unexplored continental interior or in the ocean depths - remained highly plausible at this time, making the interpretation of the fossil record far from unambiguous and the reality of extinction far from certain.
}

been poorly identified, that it has been thought possible to explain it by the suppositions of a perpetual spring, an inclination of the axis of the globe, a displacement of ocean basins, a gradual cooling of the earth, and still others equally inadequate.

Having acquainted myself with the causes of these inaccuracies, I thought I should concern myself with eliminating them. I started by reviewing all that had been done on this subject by my predecessors. I have compared afresh the bones they mentioned, which I was able to procure, with their living analogues. I have employed men to search for the bones that are concealed in the quarries in the vicinity [of Paris]; I have visited the cabinets in which they had been deposited; I began correspondence with different countries, and the savants who live in them have sent me descriptions and drawings of the fossil bones they have discovered there. I should say that I have been supported with the most ardent enthusiasm and the most noble disinterest, not only by my friends, but also by all the Frenchmen and foreigners who cultivate or love the sciences, whom it has been possi-

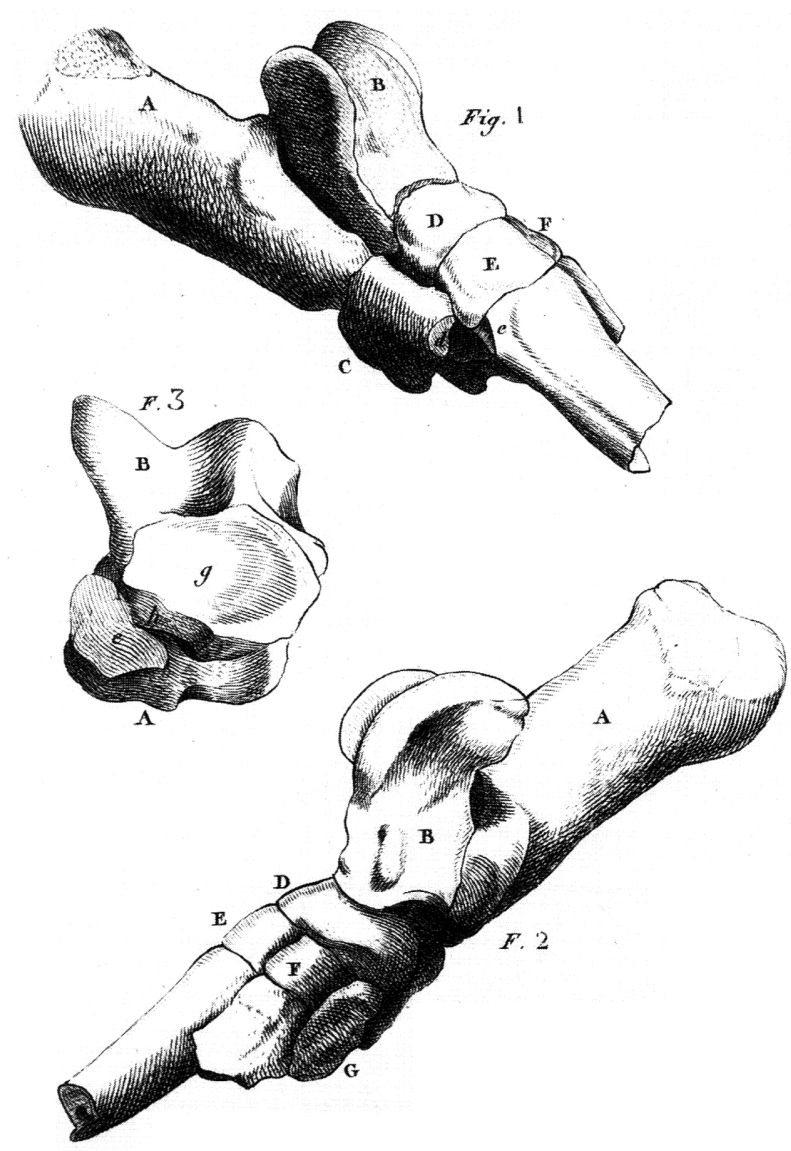

Figure 2. Fossil bones from the gypsum quarries on the outskirts of Paris, from the collection of the Parisian 'amateur' the marquis de Drée: these two views of one assemblage of bones jointly provided an almost three-dimensional 'proxy' for the real specimen. They were based on Cuvier's own drawings - they show his skill as a biological artist - and engraved, unusually, by Cuvier himself (he was taught the craft by one of the professionals who engraved his other plates). This plate dates from early in his research, before he named the Paris gypsum mammals palaeotherium and anoplotherium; it was one of those that, in his opinion, clearly established his priority over any potential rivals. (Cuvier, Ossemens Fossiles, 1812, vol. 3, unnumbered pl. "Pieds de derrières"). 
ble for me to interrogate. The result of this combined effort has been the most complete report that has yet been assembled, on the various bones that have hitherto been recovered from the bowels of the earth.

But this was not sufficient. It was necessary to determine the genus and species of each bone, of each substantial fragment of bone. It was necessary to assemble the bones belonging to the same species, to reconstruct in some way the skeletons of the animals; and then to compare the beings thus revived [ressuscités] with those that naturalists have discovered alive on the surface of our present earth, to determine their similarities and their differences. I will say more: it was necessary to penetrate within these frameworks [charpentes] to their real nature and to the way of life of the animals from which they came.

This claim is not at all as fanciful [romanesque] as it will perhaps appear to those who have no idea of the method that is followed in this kind of research.

In the living state, all the bones are attached to each other, and form an ensemble among which all the parts are coordinated. The place that each occupies is always easy to recognize by its general form, and by the number and position of their articulating facets one can judge the number and direction of those that were attached to it. Now the number, direction and shape of the bones composing each part of the body determine the movements that that part can make, and consequently the functions it can fulfill. Each part in turn is in a necessary relation with all the others, such that up to a certain point one can infer the ensemble from any one of them, and vice versa.

For example, when the teeth of an animal are such as they must be, for the animal to feed on flesh, we can be sure without further examination that the whole system of its digestive organs is adapted for this kind of food, and that its whole framework, its organs of locomotion, and even its sense organs, are made in such a way as to make it skillful in perceiving, pursuing and seizing its prey. In effect, these relations are the necessary conditions of existence of the animal, and it is evident that if things were not so this animal could not subsist.

I have chosen this example as the most palpable and the most appropriate to make conceivable the kind of reasoning that this research demands. It can easily be sensed that not all the relations of the parts are as demonstrable as these, and that one is often reduced to more tentative conjectures and less certain conclusions; but at least it is always easy to assign the degree of probability that belongs to each of these results. Besides, one does not always have to work with isolated bones. Very often it happens that almost complete limbs are discovered; sometimes no part of the skeleton has been separated from the others. In these happy cases the anatomist has almost nothing to do, for - I repeat - the skeleton determines the form of the soft parts; and imagining those in turn covered by the skin, one has the animal as it was when alive, apart from features of almost no importance such as crests, manes and other purely external parts with no influence on its inner nature.

It is by studying the fossil bones of quadrupeds on these principles, that I have reached the results that I am going to expound in a general way, and for which I shall give the evidence, with all the inferences that can be drawn from them, in the work for which the present memoir is as it were the prospectus.

First, one finds abundantly, under the soil in all countries, bones dif- ferent from those of the animals that live at the earth's surface today.

I say abundantly, for in all localities where a little care has been taken to look for them, a great number have been found. There is not a day, for example, when the labourers who work in the plaster quarries around Paris do not discover some; and if there are not more in collections, it is because collectors [curieux] have not shown enough interest in them, and the workmen have thrown them away, failing to recognize their value.

I say in all countries, because it is only those that naturalists have not yet been able to study at leisure, that have not yielded any. The soil of Siberia swarms with them. There is hardly a region of Germany, Italy, France, England, Ireland or Spain that does not have some. Ever since America has been examined by educated people living locally, it too has yielded them. Those from the banks of the Ohio have long been known; Dombey has found others in Peru. The Spaniards have reported a complete skeleton from Paraguay. The Philosophical Society of Philadelphia has just made some more known from the United States. Tartary [central Asia] has yielded some of them; and although we do not yet have any of them either from Africa (it is said that there are some at Ceuta [on the Moroccan coast] absolutely similar to those of Gibraltar) or from the large continent of New Holland [Australia], there is every reason to believe that that is simply owing to lack of research. ${ }^{(9)}$

Finally, I said that these fossil bones are almost always different from those of the animals that live on the ground that conceals them, even when otherwise they have a more or less complete resemblance to those of animals of other countries. Stony or earthy beds have no longer been forming on our continents, since they have enjoyed their natural [i.e. present] climate. That is: when animals have died, their bones, exposed to all the effects of the atmosphere, are not slow to decompose. Decomposition is fairly slow, although no less real, when these bones are buried in a loose deposit [terre meuble], as happens in our cemeteries and drainage ditches. Only stony stalactite is able, by enveloping them, to preserve them from corruption; apart from that, it is almost impossible today for fossil bones to be formed, and in effect we find none at all newly formed. ${ }^{(10)}$ Nowhere are there any human bones: all that has been said to contradict that assertion has been found false, whenever it has been possible in good faith to examine the bones that were claimed as such.

Some authors, most recently Mr Deluc, have thought that the fossil bones of quadrupeds are always found in loose deposits, the most recent of all those that envelop the core of the earth. This is not generally so. Often they are embedded in true stone, either calcareous or gypseous or even siliceous; and that not only in caves or in fissures in the rock, where - as I have just said - stalactite could have enveloped them recently, but also in the natural beds of these rocks, and sometimes of very ancient rocks. In this way those around Paris are in the middle of enormous beds of plaster, covered in turn by beds of oysters

\footnotetext{
${ }^{(9)}$ Joseph Dombey (1742-94) was a French naturalist who had travelled widely in South America. Cuvier himself had already - sensationally interpreted the famous 'Paraguay' skeleton as a giant edentate, which he named the megatherium. The United States reference is probably to Thomas Jefferson's paper on what he named the megalonix, based on fossils from Virginia and published by the American Philosophical Society the previous year.

(10) 'Stalactite' was used at this time to denote any stony precipitate or incrustation (as for example by 'petrifying springs'), not just the icicle-like forms found in some caves.
} 
and other marine shells. I even believe I have noticed a fact still more important, that has its analogies in relation to other fossils: namely that the older the beds in which these bones are found, the more they differ from those of animals that we know today.

But it is the generality of this difference that makes it the most remarkable and astonishing result that I have obtained from my research. I can now almost assert that none of the truly fossil quadrupeds that I have been able to compare precisely has been found to be similar to any of those alive today.

I am well aware that if it were only a matter of the testimony of authors, and even of respectable authors, one would find much to oppose me. Without mentioning the naturalists of old, who found 'human' fossil bones everywhere, in our own day Gouan and Spallanzani say they have found them [i.e. fossil bones identical to those of living animals]; Esper claims that the bones in the caves in Franconia are the true bones of polar bears; Pallas, that the mammoth of Siberia is in every way similar to the elephant; and so on with others. ${ }^{(11)}$

But this testimony soon evaporates under scrupulous examination; and when some doubt remains, it is because the bones being examined are such that they differ no more than from one living species to another living species. For example, all the ruminants have teeth so similar that they can be distinguished only by their size: thus two species of the same size have teeth that are absolutely alike. It is thus impossible to conclude, from the identity of the tooth of a fossil ruminant with that of a living species, that it did not come from a different animal. Apart from this single case, all the complete fossil bones that I have seen are different from those of living quadrupeds.

After lengthy research, and with the help of my predecessors and friends, I have been able to restore [rétablir] twenty-three species, all quite certainly unknown today, and which all appear to have been destroyed, but whose existence in remote ages [siècles] is attested by their remains. ${ }^{(12)}$

The one discovered longest ago is that of which the tusks yield the fossil ivory so common in Siberia [i.e., the mammoth]. It was agreed that it could be regarded as the same as the Indian elephant; but I have shown in another memoir that it differs quite substantially, and it was known before me that it usually surpassed it in size. Its remains are found all over Europe and Asia, right to the shores of the Arctic Ocean [mer glaciale]. Another almost complete skeleton of it was found last year near Gotha, in the same area in which another was found at the beginning of this [i.e. the eighteenth] century. A valley in the region of Canstadt in Swabia has furnished eight skeletons of it. Two years ago a considerable part of one was found near the village of Argenteuil, two leagues [6 miles] from Paris. It would be impossible to detail here all the places where it has been unearthed.

\footnotetext{
(11)Antoine Gouan (1733-1821) was a physician and botanist in Montpellier. Lazzaro Spallanzani (1729-99) had been professor of natural history at Pavia. Johann Friedrich Esper (1742-1810) was professor of natural history at Erlangen.

${ }^{(12)}$ The French word siècle can mean either a literal 'century' or an 'age' of indefinite duration. In either case, Cuvier's suggestion (in a paper published a few years later) of 'thousands of siècles' as the likely age of a particular fossil from the Paris gypsum - one of the uppermost and therefore youngest of the then identified 'solid' rock formations - leaves no doubt that he, like other geologists at this time, assumed that the total 'geological record' must represent a timescale of humanly unimaginable magnitude. He was certainly not, as is sometimes now implied, a young-Earth creationist avant la lettre.
}

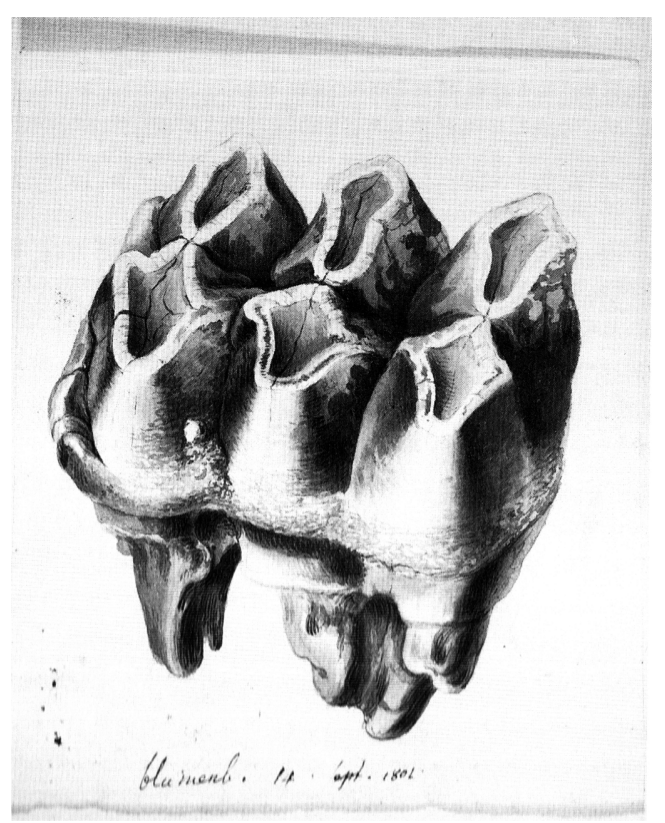

Figure 3. A watercolour image of a fossil mastodon tooth from Big Bone Lick on the Ohio, on the remote western edge of the young United States. This specimen was in the collection of Blumenbach of Göttingen, who sent this 'proxy' to Cuvier in Paris in 1801 in response to the Frenchman's appeal. It exemplifies the international and indeed global character of Cuvier's research project. (By permission of the Bibliothèque Central, Muséum National d'Histoire Naturelle, Paris [MS 630(2)])

The second of these species is that to which the English and the inhabitants of the United States have transferred the name of mammoth, which properly belongs to the first [species]. It is as large as the previous one, but its enormous teeth, armed with points, give it a distinctive character. A huge quantity of its bones is found in an area on the banks of the Ohio river, in the west of the United States; almost all those in collections in Europe and America are from there, but this species is also found in Siberia, Little Tartary [European Russia] and Italy. ${ }^{(13)}$

The third lost species is that of the long-headed rhinoceros, which, as I have shown in another memoir, is essentially different from the four or five species or varieties of living rhinoceros; it is common in Siberia and Germany. A complete one has been found embedded, with its skin and flesh, in the frozen land beside the Vilhoui, a river that flows into the Lena; which - to mention it in passing - proves that the revolution that destroyed the animals I am speaking about was extremely sudden.

The fourth lost species is that which, in a separate paper, I have named megatherium; this resembles on a large scale the quadrupeds called sloths. A complete skeleton was found in Paraguay, and is now conserved in the museum of the King of Spain; a very fine description of it has been published in Madrid. Its remains are also found in North America, for the megalonix described by Mr Jefferson does not seem to differ from it at all.

The fifth species is the large bear of which the bones are present in enormous quantities in some caves in Germany; and which has been

\footnotetext{
${ }^{(13)}$ Cuvier later named it the mastodon.
} 
recognized by [Petrus] Camper and Rosenmüller as very different from living bears. Another species of bear, which is found mixed with the preceding one in the same caves, will form my sixth species; [Adriaan] Camper the younger and I have been the first to recognise its differences. ${ }^{(14)}$ A species of carnivorous animal from the same caves, intermediate between the wolf and the hyaena, will form the seventh.

The eighth species will be the animal related to the elk, which is found in such abundance in Ireland, and of which the antlers are up to 14 feet across from one tip to the other. The English have described its bones several times.

The ninth will comprise the large fossil turtles found in several countries, which it seems should be divided into several species.

The tenth is the large animal that passes for being of the lizard genus and which is so well known under the name of the Maastricht crocodile. The Campers (father and son) have devoted much study to it, and citizen Faujas has just given a complete description of it, as well as of the quarries in which its bones are found. ${ }^{(15)}$

The eleventh will be the the very remarkable reptile embedded in the shales around Eichstätt, of which Mr Collini has described an almost complete skeleton, conserved in the museum at Mannheim. It was small, and appears to have enjoyed the ability to fly, as the little lizard called the 'dragon' does today. ${ }^{(16)}$

The twelfth is another animal, either reptile or whale, also described by Mr Collini.

Apart from these twelve species, the bones of which have been discovered or identified by others, I have collected or been the first to recognise the characters of eleven others, most of which are found in France; namely:

1. The animal whose teeth, impregnated with copper, yield the Western turquoises. Many are found at Simore in Languedoc, where there was once a quarry for these turquoises. One of its teeth has also been found near Trévoux. Dombey has reported from Peru some teeth that appear to be of the same species, many of which are impregnated in various places with native silver. This species is very close to that of Ohio.

2. A species of tapir of which the bones are also found in Languedoc, on the slopes of the Montagne Noire; it is of the same size as the living tapir, which (as is well known) comes from South America, and differs only in the form of its last molar teeth.

3. A second species of tapir, which I call 'giant' on account of its size, which equals that of an elephant; but its form does not differ at all from that of the ordinary tapir. Its remains have been found near Comminge and near Vienne in Dauphiny.

4. A species of hippopotamus, which resembles in miniature the living hippopotamus, and which is no bigger than a pig. I have found its bones in a siliceous sandstone of unknown provenance.

5.-10. The plaster quarries around Paris alone have given me six

\footnotetext{
(14)The Dutch naturalist Adriaan Gilles Camper (1759-1820) had inherited his father's fine collection, and also his competence in anatomy; he had started a substantial correspondence with Cuvier (in French, of course) the previous year.

${ }^{(15)}$ The reptile was later named the mosasaurus.

${ }^{(16)}$ Cuvier later named it ptero-dactyle (wing-fingered); in modern terms it was the first pterosaur to be discovered, and came from the famous lithographic stone at Solnhofen in Bavaria. Cosimo Alessandro Collini (1727-1806), a native of Florence, was director of the natural history museum in Mannheim; he had earlier been Voltaire's secretary in Berlin.
}

fossil species, three of which I have already spoken about elsewhere. All six are of a genus hitherto unknown, intermediate between the rhinoceros and the tapir. The differences between them consist above all in the number of digits in the feet, and in their size, which ranges from that of a horse to that of a rabbit. I have such a large number of the bones of these species that I could reconstruct [rétablir] their skeletons almost completely. ${ }^{(17)}$

11. Finally I have just recently discovered the existence near Honfleur of the bones of a species of crocodile, very close to that called the gavial or crocodile from the Ganges, but nonetheless easily distinguished from it by some striking characters.

So there, indeed, are the twenty-three species of animals unknown today that I was certain of possessing. But those concealed in the earth are not limited to these; and the following data - which I have not wanted to put on the same level as the preceding, because they do not have the same degree of certainty - are nonetheless sufficient to make us hope that we shall soon be able to enlarge this catalogue of zoological antiquities.

I arrange these still uncertain data in three classes. First I know some fossil specimens fairly similar to the equivalents in living species, but which come perhaps from species that differ in other parts. Such are:

1. The bones of quadrupeds of the tiger genus, mixed with those of the bear that I spoke of above. The specimens I have seen show hardly any difference from their analogues in the tiger and lion.

2. The head of a hyaena, described by Collini and regarded by him as that of a seal. To judge from his drawing and description, it differs in no way from that of an ordinary hyaena.

3. The bones from the rocks of Dalmatia. I have seen some teeth from there that are exactly like those of the fallow deer, but perhaps the animal differed in its antlers.

Next I have seen some other specimens that are not complete enough to recognise clearly their identity or non-identity with their [living] analogues. Such are:

1. The bones of large ruminants from the region of Verona.

2. Those of the same class from the Rock of Gibraltar.

3. The bones of rodents from the same Rock.

4. The bones of cetaceans of the dolphin genus or that of the sperm whale, which Mr Deborda d'Aureau found near Dax, and which he thought belonged to crocodiles.

5. The bones of ruminants of several different sizes, some of which are like sheep, found at Mont Abuzard near Orléans.

6. The bones from around Aix [en Provence], from Cette [Sète], etc. I have indeed seen some specimens of them, but so badly damaged that I cannot even identify their class.

7. I have also heard or read accounts of a multitude of places where bones are said to be found, but of which I have seen none. Such are the various caves in the Crapac mountains, the Harz, the Dalmatian islands, the isle of Cerigo [Kythera], the environs of Concud in Aragon, those of Cadiz, etc.

Finally, in the third class of uncertain bones I put those that are completely like living species, but which, having been found in peat bogs, could have been buried there by various causes, without having to be regarded for that reason as true fossils. Such in particular are the

\footnotetext{
${ }^{(17)}$ Cuvier later named them the Palaeotherium and Anoplotherium.
} 
bones of cattle, buffalo, aurochs and water-buffalo, which are so frequent in the marshes and peaty depths of Europe and Asia. Siberia, Germany, Holland, Scotland, and above all the Somme valley in France, have all yielded a large number of them. Here then again are several unidentified species, some of which will probably need to be added to the twenty-three which have been identified.

This remarkable number has been collected or identified in only two years, and that by a man who has utilized no other means than his own zeal and the favour of several friends of the sciences. From that can be judged what the attention of naturalists could produce, aroused by these first findings and, above all, in due time, that element so necessary for the perfection of all our knowledge. If so many lost species have been restored [rétablies] in so little time, how many must be supposed to exist still in the depths of the earth! How much will the ideas we already had about the revolutions of the globe be enlarged by these circumstances that were hitherto unknown: animals that formerly lived on the earth's surface, buried under entire mountains; between them and the present surface, traces of the successive passages of seas; an earth, a primitive nature, which was not at all submissive to the empire of mankind, and of which only some half-decomposed bones remain to us! How were these ancient organisms [êtres antiques] destroyed? Is not metaphysics itself even more embarrassed by these facts than simple physics? And is not this new production of organisms perhaps more inconceivable than any other part of the phenomenon $?^{(18)}$

It seems to me at least that what we have already recognised is important enough to commit us to further research, and I hope the friends of the sciences will want to continue to favour me. I only ask them for what it is impossible to obtain without their friendship: I mean reports of fossil bones in their possession or at their disposal. If they are willing to let me have drawings made of these bones, I will defray all the costs that those drawings entail. For my part, I shall endeavour to render them all the services that are in my power, by identifying the objects that I have at my disposal to study, and which could be useful in their own study and research. This reciprocal exchange of information [lumières] is perhaps the most noble and interesting commerce that men can have. I shall take the greatest care to record in my work the names of all those who will have contributed to its perfection, and I shall make use of the discoveries that are communicated to me, only in assigning glory to their true authors.

The most celebrated foreign naturalists, Messrs Blumenbach, Camper, Fortis, Fabbroni, Brugmans, Autenrieth, Jaeger and Wiedermann; ${ }^{(19)}$ my colleagues Lacépède, Faujas, Daubenton, Hermann, Gillet, Lelièvre, Bosc, Brongniart, Dolomieu and Fischer; ${ }^{(20)}$ the owners

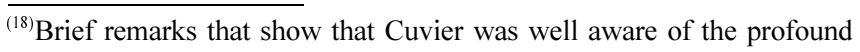
metaphysical problems, beyond 'simple physics' or causal explanation, raised by the reality and indeed ubiquity of extinction, and also conversely by what was later defined as 'the origin of species', at determinate points in the deep past.

${ }^{(19)}$ Giovanni Battista (Alberto) Fortis (1741-1803), a priest in the Augustinian order, was a naturalist in Bologna, well known for his extensive travels. Giovanni Valentino Mattia Fabbroni (1752-1822) was a naturalist who held various official positions in Florence. Sebald Justin Brugmans (1763-1819) was professor of medicine and chemistry at Leiden. Johann Hermann Ferdinand Autenrieth (1772-1835) was professor of medicine at Tübingen. Karl Christoph Friedrich von Jaeger (1773-1828) was a physician and naturalist in Stuttgart. Christian Rudolph Wilhelm Wiedemann (1779-1840) taught anatomy and surgery at the medical college in Braunschweig.
}

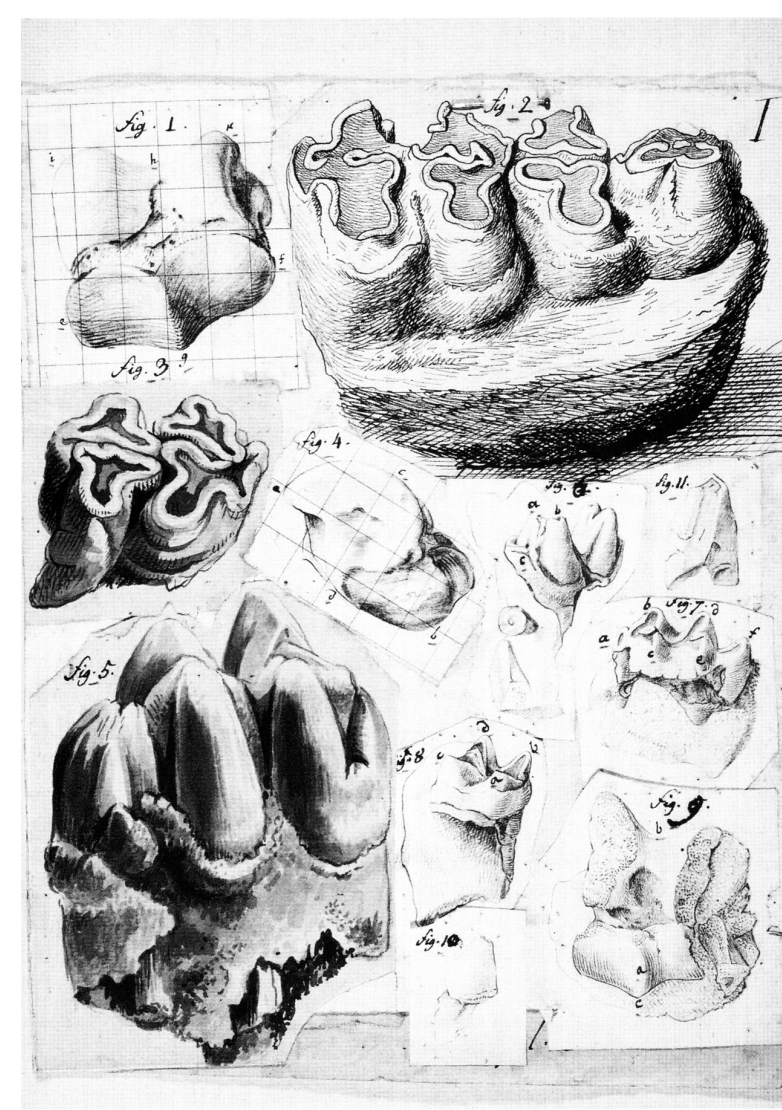

Figure 4. A typical set of images of fossil teeth and bones - these were attributed to two fossil species of hippopotamus - assembled by Cuvier ready to be engraved professionally for publication in one of his many papers in the Muséum's Annales (and subsequently republished in his collected Ossemens Fossiles). Their stylistic diversity reflects the multiplicity of Cuvier's international informants: those marked 'fig. 3' and 'fig. 5', for example, were sent to Paris by Fabbroni in Florence; 'fig. 1' and 'fig. 4' were by Cuvier himself. They have been cut out and stuck to a large sheet of paper, arranged to make the best use of the limited space on the subsequently engraved copper plate. (By permission of the Bibliothèque Central, Muséum National d'Histoire Naturelle, Paris [ MS 628])

of the finest collections, Drée, Besson and Saint-Genis; ${ }^{(21)}$ the trustees of several public museums in France and abroad: [all] have helped me

${ }^{(20)}$ Bernard Germain Étienne de la Ville-sur-Illon, count de Lacépède (1756-1825) was professor of natural history at the Muséum and a prominent politician in Paris. Johann Hermann (1738-1800) was professor of the natural and medical sciences at Strasbourg. François Pierre Nicolas Gillet de Laumont (1747-1834), Claude Hugues Lelièvre [or Le Lièvre] (1752$1835)$ and Alexandre Brongniart (1770-1847) were all members of the Corps des Mines in Paris; Brongniart - Cuvier's collaborator and nearcontemporary - had also been appointed director of the state porcelain factory at Sèvres, just outside Paris. Louis Augustin Guillaume Bosc (1759-1828) was an agriculturalist and horticulturalist in Paris. Gotthelf Fischer von Waldheim (1771-1853) was professor of natural history at Mainz (and later held a similar position in Moscow); he too counted as a 'colleague', because Mainz had been annexed by France, and its university brought within the French system.

${ }^{(21)}$ Étienne Marie Gilbert, marquis de Drée (1760-1848), and Auguste Nicholas de Saint-Genis (1741-1808) were both agronomists and naturalists in Paris; the latter also a lawyer. Besson was the owner of another important fossil collection in Paris. 
with their advice and with facts that have come to their attention, and have informed me about the specimens that are found at their disposal.

Such men should encourage others to follow their example, and I have no doubt that they will find worthy imitators. It is with this confidence that I have requested the Class of the Institute to which I have the honour to belong, to recommend me in some way to men who could be useful in my enterprise, by ordering the printing of the prospectus of my work. The favour it has shown me, in acceding to my request, is a sure guarantee of the welcome I shall have from the savants of Europe. Besides, I believe I have a kind of right to that welcome, by the highly advanced state of my work. Already I have more than three hundred drawings; fifty plates have been completely engraved and many others started; and I am waiting for nothing more, before having my book published, than the information that the present paper can procure for me.

The Botanic Garden at Paris

10 frimaire, year 9 [of the French Republic, i.e. 1 December 1800]

G. Cuvier

\section{Further reading}

Cuvier's prospectus is reprinted here (with minor corrections) in the English translation first published in Rudwick, Georges Cuvier (1997). This anthology also contains translations of extracts from his other early papers on fossil bones; his highly influential memoir (written jointly with Alexandre Brongniart) on the stratigraphy of the Paris basin; and most importantly the first edition of his Discours Préliminaire (previously available in English only in the contemporary translation edited by Robert Jameson under the misleading title of Essay on the Theory of the Earth, which wrongly implied that it belonged to a scientific genre that Cuvier in fact strongly rejected). Cuvier's correspondence network and his use of paper proxies are further described in Rudwick, 'Georges Cuvier et la collecte d'alliés internationaux' (1997), and 'Georges Cuvier's paper museum' (2000). Coleman, Georges Cuvier Zoologist (1964) remains deservedly the classic account of his zoological work, though it deals only briefly with his palaeontology and geology. Taquet, Georges Cuvier (2019), the second volume of a comprehensive biography, describes some of the most significant years of his life (1795-1803) in unrivalled detail, based on massive documentation, much of it not previously published (the original
French text of Cuvier's 'appeal' is reprinted on pp. 403-411). Complementing this, Cuvier's work on fossils is reviewed in its broader international context in Rudwick, Bursting the Limits of Time (2005), esp. pp. 349-415, 471-512, and in its sequel Worlds Before Adam (2008), esp. pp. 10-23, both of which reproduce more of his illustrations and give further information on many relevant sources both primary and secondary.

\section{References}

Coleman, W., 1964, Georges Cuvier, Zoologist: A study in the history of evolution theory. Harvard University Press, Cambridge, MA., 212 p.

Rudwick, M.J.S., 1997, Recherches sur les ossements fossiles: Georges Cuvier et la collecte des alliés internationaux. In: Blanckaert, C., Cohen, C., Corsi, P., and Jean-Louis Fischer, J.L. (Eds.), Le Muséum au premier siècle de son histoire, Éditions du Muséum national d'Histoire naturelle, Paris, v. III, pp. 591-606.

Rudwick, M.J.S., 1997, Georges Cuvier, fossil bones, and geological catastrophes. University of Chicago Press, Chicago, $318 \mathrm{p}$.

Rudwick, M.J.S., 2000, Georges Cuvier's paper museum of fossil bones. Annals of Natural History, v. 27, pp. 51-68.

Rudwick, M.J.S., 2005, Bursting the limits of time: the reconstruction of geohistory in the age of revolution. University of Chicago Press, Chicago, 732p.

Rudwick, M.J.S., 2008, Worlds before Adam: the reconstruction of geohistory in the age of reform. University of Chicago Press, Chicago, 648 p.

Taquet, P., 2019, Georges Cuvier Tome 2: anatomie d'un naturaliste. Odile Jacob, Paris, 784 p.

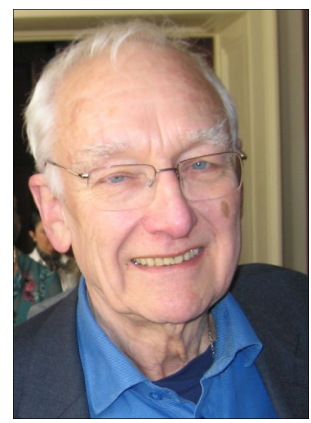

Martin J.S. Rudwick is a Professor who had a first career as a palaeontologist at Cambridge, before focussing on the history of the Earth sciences, which he taught successively at Cambridge, Amsterdam, Princeton and San Diego. He has been a member of INHIGEO since 1970, nominated an Honorary Senior Member in 2012, was president of the History of Earth Sciences Society in 2005-06, awarded the George Sarton Medal in 2007 and was given the IUGS's Tikhomirov Award in 2016. 